See Article page 265

\section{Commentary: Lessons learned during the coronavirus disease 2019 pandemic could make us better at something}

\author{
David Kalfa, MD, PhD
}

Wolfe and colleagues ${ }^{1}$ describe the case of a neonate with severe hypoxemia and refractory atrial arrhythmias related to an enlarged eustachian valve that was obstructing right ventricular inflow. Once diagnosed, the simple surgical procedure was performed and recovery was relatively quick despite a preoperative 15-day extracorporeal membrane oxygenation (ECMO) run initiated at an outside hospital.

An enlarged eustachian valve is a rare lesion and our community should definitely keep in mind this diagnosis (along with cor triatriatum dexter) when dealing with a neonate presenting with severe cyanosis and/or supraventricular arrhythmias. Probably more important than the diagnosis itself, this case report highlights 3 interesting points representing possible areas for improvement.

The first is linked to the delayed transfer of the patient to the authors' institution after remaining 13 days on ECMO. This is probably explained, as suggested by the authors, by the fact that the initial care team attributed both the hypoxia and the arrhythmias to pulmonary hypertension. This is

From the Section of Pediatric and Congenital Cardiac Surgery, Division of Cardiac, Thoracic, and Vascular Surgery, Morgan Stanley Children's Hospital/NewYork-Presbyterian, Columbia University Medical Center, New York, NY.

Disclosures: The author reported no conflicts of interest.

The Journal policy requires editors and reviewers to disclose conflicts of interest and to decline handling or reviewing manuscripts for which they may have a conflict of interest. The editors and reviewers of this article have no conflicts of interest.

Received for publication April 21, 2020; revisions received April 21, 2020; accepted for publication April 22, 2020; available ahead of print May 1, 2020.

Address for reprints: David Kalfa, MD, PhD, Section of Pediatric and Congenital Cardiac Surgery, Morgan Stanley Children's Hospital/NewYork-Presbyterian, Columbia University Medical Center, 3959 Broadway, New York, NY 10032 (E-mail: dk2757@cumc.columbia.edu).

JTCVS Techniques 2020;3:267-8

2666-2507

Copyright (C) 2020 The Authors. Published by Elsevier Inc. on behalf of The American Association for Thoracic Surgery. This is an open access article under the CC BY-NCND license (http://creativecommons.org/licenses/by-nc-nd/4.0/).

https://doi.org/10.1016/j.xjtc.2020.04.015
Check for updates

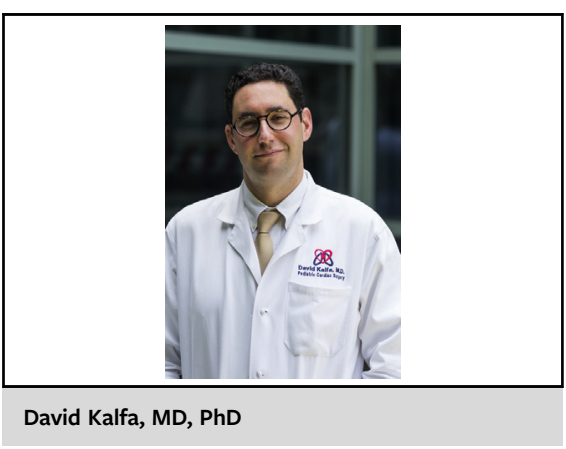

CENTRAL MESSAGE

The use of telemedicine and innovative technologies could improve communication and the sharing of expertise between remote institutions and improve patient outcomes.

(unfortunately!) not rare. Pulmonary hypertension is a very convenient and serviceable so-called black box used to explain away many symptoms or complications in neonates with congenital heart defects. Cardiologists and intensivists assessing a neonate and cardiac surgeons coming off bypass after a neonatal cardiac repair should consider primary pulmonary hypertension as the cause of hypoxia, arrhythmias, or right ventricular dysfunction only after ruling out any (residual) intracardiac lesions in the neonatal intensive care unit or in the operating room.

The second area of improvement surrounds the missed diagnosis at the referring institution. The patient's echocardiogram (see Figure 1 in Wolf and colleagues ${ }^{1}$ ) clearly demonstrated the presence of a mass within the right atrium and bowing of the septum into the left atrium. The diagnosis of an enlarged eustachian valve can be tricky for nonspecialists, but understanding that an obstructive lesion causes right to left shunt should be obvious. The long ECMO course at the outside hospital from days of life 2 to 13 raises the possibility of limited access to an echocardiographic diagnosis at the referring institution. This emphasizes the paramount importance of being able to share expertise among institutions. A sharing-economy-like organization of health care could be critical in the future to improve the care we deliver.

Finally, this report questions the ways teams working in different hospitals communicate with each other. Would better communication between the outside hospital team 
and Lurie Hospital have led to an earlier transfer, an earlier diagnosis, and a shorter ECMO run for this patient? Maybe. The coronavirus 2019 pandemic caused the use of telemedicine and video consultations to literally explode in our practice, and makes me think that the promotion of innovative technologies-including telemedicine ${ }^{2}$ as well as artificial intelligence and wireless monitoring-applied to health care in general and pediatric cardiology and cardiac imaging in particular may improve communication between remote teams and may have provided this neonate with an earlier diagnosis and earlier surgical repair.

\section{References}

1. Wolfe BL, Stephens EH, Tannous P, Kalinowski V, Lay AS, Forbess JM, et al. Obstructing eustachian valve in a newborn presenting with profound hypoxemia and atrial arrhythmias. J Thorac Cardiovasc Surg Tech. 2020;3: 265-6.

2. Satou GM, Rheuban K, Alverson D, Lewin M, Mahnke C, Marcin J, et al. Telemedicine in pediatric cardiology: a scientific statement from the American Heart Association. Circulation. 2017;135:e648-78. 